\title{
Prevalence and Associated Factors of Intimate Partner Violence during Pregnancy among Recently Delivered Women in Public Health Facilities of Hossana Town, Hadiya Zone, Southern Ethiopia
}

\author{
Tariku Laelago', Tefera Belachew ${ }^{2}$, Meseret Tamrat ${ }^{2 *}$ \\ ${ }^{1}$ Department of Clinical Nursing, Hossana College of Health Sciences, Hossana, Ethiopia \\ ${ }^{2}$ Department of Population and Family Health, Jimma University, Jimma, Ethiopia \\ Email: tarikulalago@gmail.com, teferabelachew@gmail.com, ${ }^{*}$ mamitu8@yahoo.com
}

Received 7 August 2014; revised 25 September 2014; accepted 27 October 2014

Copyright (C) 2014 by authors and OALib.

This work is licensed under the Creative Commons Attribution International License (CC BY). http://creativecommons.org/licenses/by/4.0/

(c) (i) Open Access

\section{Abstract}

Background: Intimate partner violence is recognized as a worldwide serious public health problem. It can cause serious injury, disability or death. Risk factors for intimate partner violence during pregnancy are often similar to risk factors for intimate partner violence in general. Objectives: To assess the prevalence and associated factors of intimate partner violence during pregnancy among recently delivered women in public health facilities of Hossana Town, Hadiya Zone, Southern Ethiopia, 2014. Methods: Facility based cross sectional study was conducted among 195 recently delivered women in public health facilities of Hossana Town, Hadiya zone, Southern Ethiopia from March 31-April 30, 2014. The data were collected by pretested structured questionnaire. Both bivariate and multivariate logistic regressions were done to identify predictors of intimate partner violence during pregnancy. Results: Twenty three percent $(23 \%)$ of women experienced at least one form of Intimate partner violence during pregnancy. Psychological violence was the most common form $(20 \%)$ followed by physical $(15 \%)$ and sexual violence $(12 \%)$. Alcohol drinking by the partners $(A O R=22(7.4,65.6)$, no formal education of the partners $(A O R=10.8(1.06$, $108.5)$ and planned pregnancy $(A O R=0.23(0.08,0.67)$ were significantly associated with intimate partner violence during pregnancy. Conclusion: Our study established that intimate partner violence during pregnancy was a common experience. Partners' alcohol drinking, no formal education of partners and planned pregnancy were associated with intimate partner violence during pregnancy. Health sector, police, lawyers and advocators should give due emphasis to the victims of this problem.

\footnotetext{
${ }^{*}$ Corresponding author.
}

How to cite this paper: Laelago, T., Belachew, T. and Tamrat, M. (2014) Prevalence and Associated Factors of Intimate Partner Violence during Pregnancy among Recently Delivered Women in Public Health Facilities of Hossana Town, Hadiya Zone, Southern Ethiopia. Open Access Library Journal, 1: e997. http://dx.doi.org/10.4236/oalib.1100997 


\title{
Keywords
}

\section{Intimate Partner Violence, Pregnancy, Ethiopia}

\author{
Subject Areas: Epidemiology, Psychology
}

\section{Introduction}

Intimate partner violence is recognized as a worldwide serious public health problem. It can cause serious injury, disability or death. It can also lead directly to mental disorder, substance abuse, lack of fertility control, and personal autonomy. IPV during pregnancy, particularly, is harmful as it associated with determinant outcome to both mother and her unborn baby. Women experiencing IPV during pregnancy have high rate of miscarriage, more complication during pregnancy, sexually transmitted infection (including HIV), and higher prevalence of mental disorder such as depression, anxiety, sleep and eating disorders compared to their non-abused peers [1][4].

The WHO multi-country study on women's health and domestic violence against women, which consisted of population-based surveys conducted in various countries using the same methods and definitions, found the prevalence of physical intimate partner violence in pregnancy to range between $1 \%$ in Japan city to $28 \%$ in Peru Province, with the majority of sites ranging between $4 \%$ and $12 \%$ [5].

A systemic review of Africa studies on IPV against pregnant women reported the overall prevalence of intimate partner violence during pregnancy ranged from $2.3 \%$ to $57.1 \%$. The studies also reported prevalence rates of $23 \%$ to $40 \%$ for physical, $3 \%$ to $27 \%$ for sexual and $25 \%$ to $49 \%$ for emotional intimate partner violence during pregnancy [6].

WHO multi-country study on women's health and domestic violence against women found the prevalence of intimate partner violence during pregnancy 8\% in Ethiopia province [7]. In Ethiopia only few studies are done on intimate partner violence during pregnancy, which stated only prevalence of intimate partner violence during pregnancy. Therefore, this study was conducted to assess the prevalence and associated factors of intimate partner violence during pregnancy among recently delivered women in public health facilities of Hossana Town.

\section{Methods}

\subsection{Setting and Population}

The study was conducted in Hossana Town from March 31-April 30, 2014. Hossana Town is found in Hadiya zone, Southern Ethiopia and located 232 kilometers away from Addis Ababa and 168 kilometers from Hawassa. According to records 12 women gave birth daily in public health facilities of Hossana Town [8]. Women who were giving birth (delivery) in public health facilities of Hossana Town were recruited as source population for the study. The study population was all recently delivered women (within 6 days of post-delivery) irrespective of whether the pregnancy outcome was a live or still birth during the data collection period. Women who were not mentally and physically capable of being interviewed and women admitted for abortion were excluded.

\subsection{Study Design and Sampling}

Facility based cross sectional study was conducted among recently delivered women in public health facilities of Hossana Town. The sample size was calculated by using the formula for single population proportion with assumption of $95 \%$ confidence interval, $4 \%$ degree of precision and $8 \%$ Prevalence of intimate partner violence during pregnancy in Ethiopia province [7]. By adding non-response rate 10\%, final total sample sizes was 195.

The sample size was allocated proportionally among the four public health facilities of Hossana Town. Consecutive sampling technique was undertaken by taking every woman who was present in selected health facilities during data collection period.

\subsection{Data Collection and Measurement}

Pretested structured questionnaire containing variables related to socio-demographic and economic factors of 
women and their intimate partners, reproductive health experience of women and the experience of intimate partner violence during pregnancy were used to collect data from each study subject. The questionnaire was adopted from WHO multi-country study on domestic violence [5].

The Questionnaire was first prepared in English and then translated in to Amharic and then it was translated back to English to check for its consistency. Pre-test was conducted among $5 \%$ of study subjects prior to the study. Based on the result the questionnaire was modified as necessary.

Four female nurses and two supervisors' were recruited as interviewers and as supervisors respectively. Data collectors and supervisors were trained for one day on interviewing techniques, purpose of the study, importance of privacy, sensitivity of the issue, discipline and approach to the interviewees and confidentiality of the respondents.

The principal investigator and supervisors were made a day to day on site supervision during the whole period of data collection and checked each questionnaire daily for completeness and consistency.

Intimate partner was considered as current husband, co-habited (live in the same house without formal marriage), or boyfriend. Prevalence of Intimate partner violence during pregnancy was measured by any act of physical, sexual or psychological abuse during last pregnancy by intimate partner. Physical violence includes any of one or more (slapped, pushed or shoved, hit with fist or something else that could hurt you, beaten abdomen, choked or burnt on purpose, used or threatened to use knife, gun or weapon).

Sexual violence includes any of one or more (forced into sexual intercourse when she did not want, had sexual intercourse when she did not want to because she was afraid of what partner might do, forced to do something sexual that she found degrading or humiliating). Psychological violence includes any of one or more (insult, humiliation, intimidate on purpose, threatened to hurt women or someone she cared about).

\subsection{Data Processing and Analysis}

Data editing, coding and cleaning were carried out and the data were entered into Epi-Data version 3.1 and then, it was exported into SPSS version 16.0 statistical software for analysis. Different frequency tables, graphs and descriptive summaries were used to describe the study variables.

Bivariate logistic regression analysis was used to see significant of association between the outcome and independent variables. Variables with P-value $<0.05$ in bivariate analysis were transferred to multivariate logistic regression. Odds ratios at $95 \% \mathrm{CI}$ were computed to measure the strength of the association between the outcome and the explanatory variables. Multivariate logistic regressions were performed to identify the most significant predictors of intimate partner violence and to control for confounders. P-value $<0.05$ was considered as statistically significant.

\subsection{Ethical Consideration}

Ethical clearance was taken from ethical clearance committee of the Jimma University, college Public health and medical sciences. Informed oral consent was taken from each respondent. The respondents were assured that they have full right to participate or withdraw from the study. Interviewers were trained to be aware of the effects that the questions may have on informants and how to respond based on a woman's level of distress.

A respondent may suffer physical harm if a partner finds out that she has been talking to others about her relationship with him. To minimize the risks interviewers were trained on ensuring participant safety. Privacy and confidentiality of the respondents were protected.

\section{Result}

\subsection{Socio-Demographic and Economic Characteristics}

From a total of 195 women who were identified for the study, 183 were involved in the study, yielding a response rate $94 \%$. The mean age women were $25.4 \pm 4.6$ years. About 64 (35\%) of women attained primary education and 98 (53.6\%) were housewife. One hundred seventy four (95\%) of women were married and current partners were husbands for 172 (94\%). Ninety three (50.8\%) of women lived with their current partner for six and more years with a mean of $6 \pm 4$ years. For Majority of women 137 (75\%) their last pregnancy was planned and for more than half 114 (62.3\%) of them have one to three children with a mean of $2.8 \pm 1.9$ children. The median monthly income of the respondent's was 1200 ETB. The Mean age of partners was $33.3 \pm 7.2$ years. 
Sixth six (36.1\%) of partners had attained tertiary education, 61 (33.3\%) were government employees and 67 (36.6\%) were drink alcohol (Table 1).

\subsection{Prevalence of Intimate Partner Violence during Pregnancy}

Among the women with a history of IPV during pregnancy 36 (20\%) had experienced psychological violence, 22 (12\%) sexual violence and 27 (15\%) physical violence. Among physical violence slapping 27 (14.8\%) was the commonest form of violence. Physically forced to do sexual intercourse $22(12 \%)$ and insulting $36(19.7 \%)$ were commonest form of sexual and emotional violence respectively. Forty three (23\%) of women experienced at least one form of IPV during pregnancy (Table 2).

Table 1. Socioeconomic and demographic characteristics of women and partners, Hossana, April 2014.

\begin{tabular}{|c|c|c|}
\hline Variables & Frequency & Percentage \\
\hline \multicolumn{3}{|l|}{ Age of women in years $(n=183)$} \\
\hline $18-24$ & 75 & 41 \\
\hline $25-29$ & 67 & 36.6 \\
\hline $30-34$ & 28 & 15.3 \\
\hline $35-38$ & 13 & 7.1 \\
\hline \multicolumn{3}{|l|}{ Age of partners in years $(n=183)$} \\
\hline $20-24$ & 18 & 9.8 \\
\hline $25-29$ & 37 & 20.2 \\
\hline $30-34$ & 40 & 21.9 \\
\hline$\geq 35$ & 88 & 48.1 \\
\hline \multicolumn{3}{|c|}{ Educational status of women $(n=183)$} \\
\hline No formal education & 33 & 18 \\
\hline Primary education & 68 & 37 \\
\hline Secondary education & 42 & 23 \\
\hline Tertiary education & 40 & 22 \\
\hline \multicolumn{3}{|c|}{ Educational status of partners $(n=183)$} \\
\hline No formal education & 14 & 7.7 \\
\hline Primary education & 50 & 27.3 \\
\hline Secondary education & 53 & 29.0 \\
\hline Tertiary education & 66 & 36 \\
\hline \multicolumn{3}{|c|}{ Occupational status of women $(n=183)$} \\
\hline Housewife & 98 & 53.6 \\
\hline Student & 16 & 8.7 \\
\hline Merchant & 31 & 16.9 \\
\hline Government employee & 33 & 18.0 \\
\hline Non-government employee & 3 & 1.6 \\
\hline Other $^{*}$ & 2 & 1.1 \\
\hline \multicolumn{3}{|c|}{ Occupational status of partners $(n=183)$} \\
\hline Farmer & 48 & 26.2 \\
\hline Merchant & 47 & 25.7 \\
\hline Government employee & 61 & 33.3 \\
\hline Non-government employee & 10 & 5.5 \\
\hline Others $^{* *}$ & 17 & 10.2 \\
\hline \multicolumn{3}{|l|}{ Marital status of women $(n=183)$} \\
\hline Married & 174 & 95.1 \\
\hline Never married & 5 & 2.7 \\
\hline Divorced & 4 & 2.2 \\
\hline
\end{tabular}




\section{Continued}

\begin{tabular}{|c|c|c|}
\hline Current partner $(n=183)$ & & \\
\hline Husband & 172 & 94.0 \\
\hline Cohabited & 4 & 2.2 \\
\hline Boyfriend & 7 & 3.8 \\
\hline \multicolumn{3}{|c|}{ Duration of relationship with partner $(n=183)$} \\
\hline$<2$ year & 25 & 13.7 \\
\hline 2 to 5 year & 65 & 35.5 \\
\hline$\geq 6$ years & 93 & 50.8 \\
\hline \multicolumn{3}{|l|}{ Number of pregnancy $(n=183)$} \\
\hline One or two & 92 & 50.3 \\
\hline Three or above & 91 & 49.7 \\
\hline \multicolumn{3}{|c|}{ Last pregnancy planned $(\mathrm{n}=183)$} \\
\hline Yes & 137 & 75 \\
\hline No & 46 & 25 \\
\hline \multicolumn{3}{|l|}{ Number of children $(n=181)$} \\
\hline No child & 1 & 0.6 \\
\hline One to three children & 120 & 66.3 \\
\hline Four and above children & 60 & 33.1 \\
\hline \multicolumn{3}{|c|}{ Average monthly income $(n=180)$} \\
\hline$<1200$ ETB & 98 & 54.4 \\
\hline$\geq 1200 \mathrm{ETB}$ & 82 & 45.6 \\
\hline \multicolumn{3}{|c|}{ Alcohol drinking by partners $(n=183)$} \\
\hline Yes & 67 & 36.6 \\
\hline No & 116 & 63.4 \\
\hline
\end{tabular}

*Other—daily workers, ${ }^{* *}$ others—daily workers, no job, preacher, student, driver.

Table 2. Prevalence of intimate partner violence during pregnancy among recently delivered women, Hossana, April 2014.

\begin{tabular}{|c|c|c|}
\hline Violence item & Frequency & Percentage \\
\hline \multicolumn{3}{|l|}{ Physical violence } \\
\hline Slapped & 27 & 14.8 \\
\hline Pushed & 19 & 10.4 \\
\hline Hit with fist & 12 & 6.6 \\
\hline Beaten in the abdomen & 6 & 3.3 \\
\hline Chocked or burned on purpose & 4 & 2.2 \\
\hline Threatened to use or actual used weapon & 5 & 2.7 \\
\hline Overall prevalence of physical abuse & 27 & 15 \\
\hline \multicolumn{3}{|l|}{ Sexual violence } \\
\hline Physically forced to do sexual intercourse & 22 & 12 \\
\hline Had sexual intercourse when you do not want & 19 & 10.4 \\
\hline Forced you to do something sexual that you found humiliating & 3 & 1.6 \\
\hline Overall prevalence of sexual violence & 22 & 12 \\
\hline \multicolumn{3}{|l|}{ Psychological violence } \\
\hline Insulted & 36 & 19.7 \\
\hline Humiliated & 30 & 16.4 \\
\hline Had done something to scare you & 20 & 10.9 \\
\hline Had threatened to hurt you & 22 & 12 \\
\hline Overall prevalence of emotional or psychological violence & 36 & 20 \\
\hline Over all prevalence of intimate partner violence pregnancy & 43 & 23 \\
\hline
\end{tabular}




\subsection{Factors Associated with Intimate Partner Violence during Pregnancy}

Bivariate and multivariate logistic regression analyses were done to identify factors associated with intimate partner violence during pregnancy. On bivariate analyse age of partners, education status of women, educational status of partners, number of pregnancy, Last pregnancy planned and alcohol drinking by partners had association with intimate partner violence during pregnancy.

Although the bivariate analysis showed association of intimate partner violence with six independent variables, only alcohol drinking by partners, educational status of partners and last pregnancy planned were associated with IPV on multivariate analysis. Multivariate analysis revealed that intimate partner violence during pregnancy was 22 times higher among women whose current partners drank alcohol as compared to those women whose partner did not drink alcohol $(A O R=22(7.4,65.6))$. Similarly, partners who had no formal education were 10.8 times more likely to abuse their wives as compared to those who had tertiary education (AOR $=10.8(1.06,108.5))$ and Women whose last pregnancy was planned were 77 percent less likely to be abused than women whose pregnancy was not planned $(\mathrm{AOR}=0.23(0.08,0.67))($ Table 3$)$.

\section{Discussion}

In this study an attempt has been made to assess the prevalence and associated factors of intimate partner violence during pregnancy among recently delivered women.

The current study demonstrated that the overall prevalence of IPV is consistent with studies done in other parts of Africa. A systemic review of Africa studies on IPV against pregnant women reported the overall prevalence of intimate partner violence during pregnancy ranged from $2.3 \%$ to $57.1 \%$ [6]. The studies also reported prevalence rates of $23 \%$ to $40 \%$ for physical violence, which is higher than current study, $3 \%$ to $27 \%$ for sexual, which is consistent with current study and $25 \%$ to $49 \%$ for emotional intimate partner violence during pregnancy

Table 3. Factors related to experiencing of intimate partner violence during pregnancy, Hossana, April 2014.

\begin{tabular}{|c|c|c|c|c|}
\hline Variables & \multicolumn{2}{|c|}{ Intimate partner violence } & \multirow[t]{2}{*}{ COR at $95 \%$ CI } & \multirow[t]{2}{*}{ AOR at $95 \%$ CI } \\
\hline Alcohol drinking & Yes & No & & \\
\hline Yes & 37 (86\%) & $14(5.2 \%)$ & $22.6(8.7,58.6)^{*}$ & $22(7.4,65.6)^{*}$ \\
\hline No & $6(14 \%)$ & $110(78.6 \%)$ & 1 & 1 \\
\hline \multicolumn{5}{|l|}{ Last pregnancy planned } \\
\hline Yes & $19(44.2 \%)$ & $118(84.3 \%)$ & $0.15(0.07,0.34)^{*}$ & $0.23(0.08,0.67)^{*}$ \\
\hline No & $24(55.8 \%)$ & $22(15.7 \%)$ & 1 & 1 \\
\hline \multicolumn{5}{|l|}{ Number of pregnancy } \\
\hline One or two & 15 (34.9\%) & $76(54.3 \%)$ & $0.451(0.22,0.92)^{*}$ & $0.902(0.262,3.102)$ \\
\hline Three or more & $28(65.1 \%)$ & $64(45.7 \%)$ & 1 & 1 \\
\hline \multicolumn{5}{|l|}{ Age of partners } \\
\hline $20-24$ & $4(9.3 \%)$ & $14(10 \%)$ & $0.612(0.185,2.029)$ & $0.478(0.09,2.58)$ \\
\hline $25-29$ & $5(11.6 \%)$ & $32(22.9 \%)$ & $0.335(0.118,0.951)^{*}$ & $0.724(0.16,3.34)$ \\
\hline $30-34$ & $6(14 \%)$ & $34(24.3 \%)$ & $0.378(0.142,1.005)$ & $0.442(0.118,1.652)$ \\
\hline$\geq 35$ & $28(65.1 \%)$ & $60(42.9 \%)$ & 1 & 1 \\
\hline \multicolumn{5}{|c|}{ Educational status of women } \\
\hline No formal education & $12(27.9 \%)$ & $21(15 \%)$ & $3.23(1.056,9.933)^{*}$ & $0.275(0.024,3.225)$ \\
\hline Primary education & 17 (39.5\%) & $51(36.4 \%)$ & $1.88(0.676,5.275)$ & $0.383(0.05,2.84)$ \\
\hline Secondary education & $8(18.6 \%)$ & $34(24.3 \%)$ & $1.33(0.42,4.25)$ & $0.626(0.123,3.533)$ \\
\hline Tertiary education & $6(14 \%)$ & $34(24.3 \%)$ & 1 & 1 \\
\hline \multicolumn{5}{|c|}{ Educational status of partners } \\
\hline No formal education & $8(18.6 \%)$ & $6(4.3 \%)$ & $6.667(1.928,23.05)^{*}$ & $10.8(1.06,108.5)^{*}$ \\
\hline Primary education & $14(32.6 \%)$ & $36(25.7 \%)$ & $1.94(0.795,4.756)$ & $0.757(1.345,0.205)$ \\
\hline Secondary education & $10(23.3 \%)$ & $43(30.7 \%)$ & $1.163(0.45,2.99)$ & $1.136(0.229,5.626)$ \\
\hline Tertiary education & $11(25.6 \%)$ & 55 (39.3\%) & 1 & 1 \\
\hline
\end{tabular}

"P-value $<0.05$. 
which is higher than current study. The wide-ranging estimates may be a result of the different types of violence the researchers inquire about, use of different violence measures, and differences in the populations sampled and cultural differences between the countries.

The overall prevalence of intimate violence during pregnancy and prevalence of psychological violence in current study is lower than Kenyan study which showed that the prevalence of intimate partner violence during pregnancy was $37 \%$ and the prevalence of psychological violence being $29 \%$. The prevalence of physical violence in current study is higher than the Kenyan study but prevalence of sexual violence is consistent, which showed that sexual $12 \%$ and physical $10 \%$ [9]. The difference may be due to the difference in culture and norms between the two countries. Similarly IPV during pregnancy is higher than the WHO study of Ethiopia which showed $8 \%$ of women were abused during pregnancy [7].

In this study planned pregnancy had association with intimate partner violence during pregnancy. This is consistent with Study done in Bangladesh and in ten DHS countries which showed significant association of unplanned pregnancy and violence [10] [11]. The explanation for this is when pregnancy is unplanned, conflict may be raised between couples and violence may be followed based on this conflict. In contrary to current study, study done in Nigeria and South Africa did not found significant association with experiencing violence and unplanned pregnancy [12] [13]. This may be due to they recruited the women who had made at least one previous visit to the antenatal clinic, because of this women who had unplanned pregnancy and abused may not participate in the study.

Educational status of partners was associated with intimate partner violence during pregnancy showing that partner who had no formal education was more likely to abuse his wife than partner who had tertiary education. This is consistent with study done in Kenya and Bangladesh which showed that partner who attends tertiary education is protective against intimate partner violence during pregnancy and husband's education beyond 10th grade was associated in both rural and urban with lower odds of violence during pregnancy [9] [12] [14]. This could be due to when partner education status increase the ability to negotiate may increase and as a result the violence will decrease. In contrary to current study, study conducted in Pakistan showed no association between husband education and abuse [15].

Partner alcohol drinking was found to be associated with intimate partner violence during pregnancy. This finding is consistent with the study done in Kenya, South Africa and in other African countries [6] [9] [11]. This may be due to alcohol drinking can cause aggression and can result for violent behaviour.

\subsection{Strength of the Study}

The strength of this study is the use of validated instrument of WHO multi-country study on VAW.

\subsection{Limitation of the Study}

Since this study was a cross sectional in design it is difficult to establish causes and effect relationships among outcome of interest and explanatory variable. The team interviewed only women as proxy respondents for their husbands/partners, and hence relies on women's reports only. This can be biased when it comes to reporting on partners' characteristics. Information about violence was self-reported, which may have led to recall bias. The sensitive nature of the topic and its proneness to response bias may lead to under-reporting of the true extent of the abuse. Important explanatory variables such as residence, marriage type, Antenatal follow up and history of abuse were not collected in the survey. Wide confidence intervals were observed in this study and it may affect precision. This may be due to small sample size; therefore interpretation of the finding shall take in to account this.

\section{Conclusion}

This study revealed that intimate partner violence during pregnancy was a common experience. Almost one out of four women was abused by their intimate partner. Among women with history of IPV psychological violence was the common type followed by physical and sexual violence. Alcohol drinking by partners; no formal education of partners and planned pregnancy were found to be significant predictor of intimate partner violence during pregnancy. Health sectors should train health care providers on how to screen, how to approach the topic, how to treat and counsel the victims and follow up of victims of abuse. Polices, lawyer and advocates should ensure that women seeking justice and protection are treated appropriately. This study examined factors associated with 
experiencing any type of violence (physical and/or sexual and/or psychological) during pregnancy. With large sample, it would be better to examine factors associated with each of three types of intimate partner violence during pregnancy.

\section{Acknowledgements}

We would like to thank the followings for their contribution: Jimma University, college of public health and medical science, for providing us ethical clearance; our data collectors, Clients, staffs of the Hospital and health centers who participated directly or indirectly in the study.

\section{Authors' Contributions}

Tariku Laelago wrote the proposal, participated in data collection, analyzed the data and drafted the paper. Tefera Belachew and Meseret Tamrat approved the proposal, participated in data analysis and revised subsequent draft of the paper. All authors read and approved the final manuscript.

\section{Competing Interests}

The authors declare that they have no competing interests.

\section{References}

[1] Ahmed, S., Koenig, M.A. and Stephenson, R. (2006) Effects of Domestic Violence on Perinatal and Early-Childhood Mortality: Evidence from North India. American Journal of Public Health, 96, 1423-1428. http://dx.doi.org/10.2105/AJPH.2005.066316

[2] Boy, A. and Salihu, H.M. (2004) Intimate Partner Violence and Birth Outcomes: A Systematic Review. International Journal of Fertility and Women's Medicine, 49, 159-164. http://www.ncbi.nlm.nih.gov/pubmed/15481481

[3] Campbella, J.C., Batya, M.L., Ghandourb, R.M., Stockmanc, J.K., Franciscod, L. and Wagmanb, J. (2008) The Intersection of Intimate Partner Violence against Women and HIV/AIDS: A Review. International Journal of Injury Control and Safety, 15, 221-231. http://dx.doi.org/10.1080/17457300802423224

[4] Dunkle, K.L., Jewkes, R.K., Brown, H.C., Gray, G.E., McIntryre, J.A. and Harlow, S.D. (2004) Gender-Based Violence, Relationship Power, and Risk of HIV Infection in Women Attending Antenatal Clinics in South Africa. Lancet, 363, 1415-1421. http://dx.doi.org/10.1016/S0140-6736(04)16098-4

[5] Garcia-Moreno, C., Jansen, H.A., Ellsberg, M., Heise, L. and Watts, C. (2005) WHO Multi-Country Study on Women's Health and Domestic Violence against Women: Initial Result on Prevalence, Health Outcomes and Women's Responses. World Health Organization.

[6] Shamu, S., Abrahams, N., Temmerman, M., Musekiwa, A. and Zarowsky, C. (2011) A Systematic Review of African Studies on Intimate Partner Violence against Pregnant Women. Prevalence and Risk Factors. PLoS One, 6, e17591. http://dx.doi.org/10.1371/journal.pone.0017591

[7] WHO (2013) Intimate Partner Violence during Pregnancy. http://whqlibdoc.who.int/hq/2011/WHO_RHR_11.35_eng.pdf

[8] Annual Report and Performance of Hadiya Zone Health Department 2013/2014.

[9] Makayoto, L.A., Omolo, J., Kamweya, A.M., Harder, V.S. and Muta, J. (2013) Prevalence and Associated Factors of Intimate Partner Violence among Pregnant Women Attending Kisumu District Hospital. Maternal and Child Health Journal, 13, 441.

[10] Hindin, M.J., Kishor, S. and Ansara, D.L. (2008) Intimate Partner Violence among Couples in 10 DHS Countries: Predictors and Health Outcomes. Macro International, Calverton, 18.

[11] Matseke, G., Peltzer, K. and Mlambo, G. (2012) Partner Violence and Associated Factors among Pregnant Women in Nkangala District, Mpumalanga. SAJOG, 18, 77.

[12] Fawole, A.O., Hunyinbo, K.I. and Fawole, O.I. (2008) Prevalence of Violence against Pregnant Women in Abeokuta, Nigeria. Australian and New Zealand. Journal of Obstetrics and Gynaecology, 48, 405-414. http://dx.doi.org/10.1111/j.1479-828X.2008.00868.x

[13] Wathen, C.N., Jamieson, E., Wilson, M., Daly, M., Worster, A. and MacMillan, H.L. (2007) Risk Indicators to Identify Intimate Partner Violence in the Emergency Department. Open Medicine, 1, e113-e122.

[14] Naved, R.T. and Persson, L.Å. (2008) Factors Associated with Physical Spousal Abuse of Women during Pregnancy in Bangladesh. International Family Planning Perspectives, 34, 75. 
[15] Fikree, F.F., Jafarey, S.N., Korejo, R., Afshan, A. and Durocher, J.M. (2006) Intimate Partner Violence before and during Pregnancy Pakistan. Journal of Pakistan Medical Association, 56, 256.

\section{Abbreviations and Acronyms}

AOR: Adjusted odd ratio

CI: Confidence interval

COR: Crude odd ratio

DHS: Demographic health survy

ETB: Ethiopian birr

HIV: Human immune deficiency virus

IPV: Intimate partner violence

VAW: Violence against women

WHO: World health organization 